Unit Root Tests in Time Series Volume 1 
Palgrave Texts in Econometrics

General Editor: Kerry Patterson

Titles include:

Simon P. Burke and John Hunter

MODELLING NON-STATIONARY TIME SERIES

Michael P. Clements

EVALUATING ECONOMETRIC FORECASTS OF ECONOMIC AND FINANCIAL VARIABLES

Lesley Godfrey

BOOTSTRAP TESTS FOR REGRESSION MODELS

Terence C. Mills

MODELLING TRENDS AND CYCLES IN ECONOMIC TIME SERIES

Kerry Patterson

A PRIMER FOR UNIT ROOT TESTING

Kerry Patterson

UNIT ROOT TESTS IN TIME SERIES VOLUME 1

Key Concepts and Problems

Palgrave Texts in Econometrics

Series Standing Order ISBN 978-1-4039-0172-9 (hardback) 978-1-4039-0173-6 (paperback)

(outside North America only)

You can receive future titles in this series as they are published by placing a standing order. Please contact your bookseller or, in case of difficulty, write to us at the address below with your name and address, the title of the series and the ISBNs quoted above.

Customer Services Department, Macmillan Distribution Ltd, Houndmills, Basingstoke, Hampshire RG21 6XS, England 


\section{Unit Root Tests in Time Series Volume 1}

Key Concepts and Problems

Kerry Patterson

palgrave macmillan 


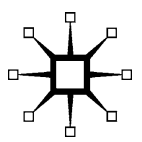

(C) Kerry Patterson 2011

Softcover reprint of the hardcover 1st edition 2011 978-0-230-25024-6

All rights reserved. No reproduction, copy or transmission of this publication may be made without written permission.

No portion of this publication may be reproduced, copied or transmitted save with written permission or in accordance with the provisions of the Copyright, Designs and Patents Act 1988, or under the terms of any licence permitting limited copying issued by the Copyright Licensing Agency, Saffron House, 6-10 Kirby Street, London EC1N 8TS.

Any person who does any unauthorized act in relation to this publication may be liable to criminal prosecution and civil claims for damages.

The author has asserted his right to be identified as the author of this work in accordance with the Copyright, Designs and Patents Act 1988.

First published 2011 by PALGRAVE MACMILLAN

Palgrave Macmillan in the UK is an imprint of Macmillan Publishers Limited, registered in England, company number 785998, of Houndmills, Basingstoke, Hampshire RG21 6XS.

Palgrave Macmillan in the US is a division of St Martin's Press LLC, 175 Fifth Avenue, New York, NY 10010.

Palgrave Macmillan is the global academic imprint of the above companies and has companies and representatives throughout the world.

Palgrave ${ }^{\circledR}$ and Macmillan ${ }^{\circledR}$ are registered trademarks in the United States, the United Kingdom, Europe and other countries

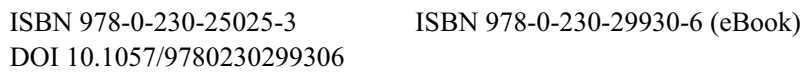

This book is printed on paper suitable for recycling and made from fully managed and sustained forest sources. Logging, pulping and manufacturing processes are expected to conform to the environmental regulations of the country of origin.

A catalogue record for this book is available from the British Library.

Library of Congress Cataloging-in-Publication Data

Patterson, K. D.

Unit root tests in time series volume 1 : key concepts and problems / Kerry Patterson.

p. $\mathrm{cm}$.

Includes bibliographical references and index.

1. Econometrics. 2. Time-series analysis. I. Title.

HB139.P374 2010

$519.5^{\prime} 5-\mathrm{dc} 22$

2010027477

$\begin{array}{llllllllll}10 & 9 & 8 & 7 & 6 & 5 & 4 & 3 & 2 & 1\end{array}$

$\begin{array}{llllllllll}20 & 19 & 18 & 17 & 16 & 15 & 14 & 13 & 12 & 11\end{array}$ 
To Bella and a continuing treasure at Auton Farm 



\section{Contents}

Detailed Contents ix

List of Tables $\quad$ xxii

List of Figures xxvii

Symbols and Abbreviations $\quad$ xxxii

Preface $\quad$ xxxiii

1 Introduction to Random Walks and Brownian Motion 1

2 Why Distinguish Between Trend Stationary and

3 An Introduction to ARMA models $\quad 68$

4 Bias and Bias Reduction in AR Models $\quad 123$

5 Confidence Intervals in AR Models $\quad 158$

6 Dickey-Fuller and Related Tests 189

7 Improving the Power of Unit Root Tests 260

8 Bootstrap Unit Root Tests 319

9 Lag Selection and Multiple Tests 348

10 Testing for Two (or More) Unit Roots 385

11 Tests with Stationarity as the Null Hypothesis 434

12 Combining Tests and Constructing Confidence Intervals 497

13 Unit Root Tests for Seasonal Data 519

Appendix 1: Random Variables; Order Notation 597

Appendix 2: The Lag Operator and Lag Polynomials 603

$\begin{array}{ll}\text { References } & 619\end{array}$

Author Index $\quad 633$

$\begin{array}{ll}\text { Subject Index } & 637\end{array}$ 



\section{Detailed Contents}

List of Tables $\quad$ xxii

List of Figures $\quad$ xxvii

Symbols and Abbreviations $\quad$ xxxii

Preface xxxiii

1 Introduction to Random Walks and Brownian Motion 1

$\begin{array}{lll}1.1 & \text { Random walks } & 3\end{array}$

1.1.1 The random walk as a partial sum process (psp) 4

1.1.2 Random walks: visits to the origin (sign changes and reflections) 5

1.1.3 Random walk: an example of a stochastic process $\quad 7$

1.1.4 Random walk: an example of a nonstationary process $\quad 8$

1.1.4.i A strictly stationary process 8

1.1.4.ii Weak or second-order stationarity (covariance stationarity) 9

1.1.4.iii The variance of a random walk increases over time 10

1.1.4.iv The autocovariances of a random walk are not constant 11

1.1.5 A simple random walk with Gaussian inputs 12

$\begin{array}{ll}\text { 1.1.6 Variations on the simple random walk } & 12\end{array}$

$\begin{array}{lll}\text { 1.1.7 An empirical illustration } & 14\end{array}$

1.1.8 Finer divisions within a fixed interval: towards
Brownian motion

$\begin{array}{lll}1.2 & \text { Definition of Brownian motion } & 18\end{array}$

$\begin{array}{lll}1.3 & \text { Functional central limit theorem (FCLT) } & 19\end{array}$

1.4 Continuous mapping theorem (CMT) 21

1.5 Background to unit root and related tests 23

1.5.1 What is a unit root? 23

1.5.1.i Generalising the random walk 23

1.5.1.ii Integrated of order d: the I(d) notation 25

1.5.2 The development of unit root tests 25

1.6 Are unit root processes of interest? 29

1.6.1 Are there constant 'great ratios'? 29

1.6.2 Purchasing power parity 30

1.6.3 Asset returns 33

1.7 Concluding remarks 35

Questions 36 
2 Why Distinguish Between Trend Stationary and Difference Stationary Processes?

$\begin{array}{ll}2.1 & \text { What accounts for the trend? } \\ 39\end{array}$

2.2 Inappropriate detrending and inappropriate first differencing 40

2.2.1 Spurious detrending 41

2.2.1.i Limit distributions and test statistics $\quad 41$

2.2.1.ii Spurious periodicity 42

2.2.2 Spurious first differencing $\quad 46$

2.2.2.i The over-differencing effect 46

2.2.2.ii Implications of over-differencing for the spectral density function $\quad 46$

$\begin{array}{lll}2.3 & \text { Persistence and the impact of shocks } & 47\end{array}$

2.3.1 The role of shocks 48

2.3.1.i A simple model 48

2.3.1.ii More complex models 49

2.4 Measures of the importance of the unit root 51

2.4.1 The variance ratio for a simple random walk 51

2.4.2 Interpretation in terms of autocorrelations and
spectral density

2.4.3 Interpretation in terms of a permanent-temporary (P-T) decomposition $\quad 54$

2.4.4 Interpretation in terms of unconditional and conditional variances $\quad 55$

2.4.5 The relationship between the persistence measure and the variance ratio $\quad 56$

2.5 Illustration: US GNP $\quad 57$

2.6 Unit root tests as part of a pre-test routine 61

$\begin{array}{lll}2.6 .1 & \text { Spurious regression } & 61\end{array}$

$\begin{array}{lll}2.7 & \text { Concluding Remarks } & 64\end{array}$

Questions $\quad 64$

3 An Introduction to ARMA Models $\quad 68$

$\begin{array}{lll}3.1 & \operatorname{ARMA}(\mathrm{p}, \mathrm{q}) \text { models } & 69\end{array}$

$\begin{array}{lll}3.1 .1 & \text { Deterministic terms } & 70\end{array}$

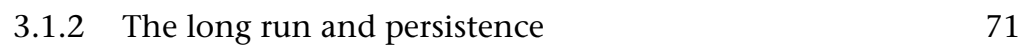

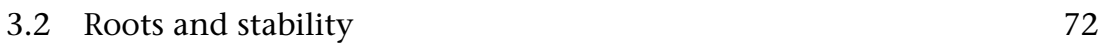

3.2.1 The modulus of the roots of the AR polynomial must $\begin{array}{ll}\text { lie outside the unit circle } & 72\end{array}$

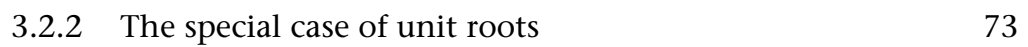

3.2.2.i Unit roots in the AR polynomial 73

3.2.2.ii A notational convention $\quad 74$

3.2.2.iii Unit roots in the MA polynomial 75 
3.3 Infinite moving average representation of the ARMA model 76

3.3.1 Examples 76

$\begin{array}{lll}\text { 3.3.2 The general MA representation } & 77\end{array}$

3.3.3 Inversion of the MA polynomial 78

3.4 Approximation of MA and ARMA models by a 'pure' AR model 79

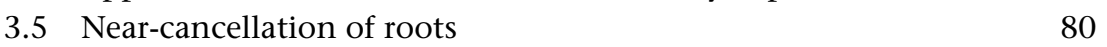

3.6 The Beveridge-Nelson (BN) decomposition of a lag polynomial 81

3.6.1 The BN decomposition of a lag polynomial 81

3.6.2 The BN decomposition for integrated processes
(optional on first reading)

3.6.2.i The BN decomposition in terms of the ARMA lag polynomials 83

3.6.2.ii Precise and efficient computation of the BN decomposition 86

3.6.2.iii Illustrations of the BN decomposition $\quad 87$

3.7 The Dickey-Fuller (DF) decomposition of the lag polynomial and the ADF model $\quad 89$

3.7.1 The DF decomposition 90

3.8 Different ways of writing the ARMA model 91

3.8.1 Alternative ways of representing the dynamics 92

3.8.1.i An error dynamics model 92

3.8.1.ii Common factor model 94

3.8.1.iii Direct specification 96

3.8.2 A pseudo t test of the null hypothesis, $\gamma=0: \hat{\tau} \quad 98$

$\begin{array}{lll}\text { 3.8.3 DF n-bias tests: } \hat{\delta} & 98\end{array}$

3.9 An outline of maximum likelihood (ML) estimation and testing for a unit root in an ARMA model 100

$\begin{array}{lll}3.9 .1 & \text { ML estimation } & 100\end{array}$

3.9.1.i The ARMA model (Shin and Fuller, 1998) 100

3.9.1.ii The log-likelihood functions 101

3.9.1.iii AR(1), stationary case with niid errors $\quad 102$

3.9.2 Likelihood-based unit root test statistics 104

3.9.2.i ML: conditional and unconditional approaches 105

3.9.3 Estimation, critical values and finite sample performance 107

3.9.3.i Estimation 107

3.9.3.ii Asymptotic distributions 108

3.9.3.iii Critical values and estimation $\quad 108$

3.9.3.iv Finite sample performance $\quad 109$

$\begin{array}{ll}3.10 \text { Illustration: UK car production } & 110\end{array}$

3.10.1 Estimated model and test statistics $\quad 111$

3.10.2 The BN decomposition of the car production data 112 
$\begin{array}{ll}3.11 \text { Concluding remarks } & 115\end{array}$

Questions 116

4 Bias and Bias Reduction in AR Models $\quad 123$

$\begin{array}{lll}4.1 & \text { Finite sample bias of the LS estimator } & 124\end{array}$

$\begin{array}{lll}4.1 .1 & \text { The bias to order } \mathrm{T} & 124\end{array}$

4.1.2 First-order bias and the long-run multiplier $\quad 127$

$\begin{array}{lll}4.2 & \text { Bias reduction } & 128\end{array}$

4.2.1 Total bias and first-order bias $\quad 129$

4.2.1.i Total bias 129

4.2.1.ii First-order bias 129

4.2.2 First-order unbiased estimators in the AR model 129

$\begin{array}{lll}\text { 4.2.3 Simulating the bias } & 131\end{array}$

4.2.3.i Illustration of linear bias correction using the $\mathrm{AR}(1)$ model 132

4.2.4 Constant bias correction 133

4.2.5 Obtaining a linear bias corrected estimator 133

4.2.6 Linear bias correction in AR(p) models, $\mathrm{p} \geq 2$

$\begin{array}{lll}4.2 .7 & \text { The connection } & 135\end{array}$

4.2.8 The variance and mean squared error of the FOBC
estimators

4.2.8.i Mean squared error comparison $\quad 138$

$\begin{array}{lll}4.3 & \text { Recursive mean adjustment } & 138\end{array}$

$\begin{array}{lll}\text { 4.3.1 AR(1) model } & 139\end{array}$

4.3.1.i Constant mean 139

4.3.1.ii Trend in the mean 140

4.3.2 Extension to AR(p) models 141

4.3.2.i Constant mean, AR(p) models 141

4.3.2.ii Trend in the mean, AR(p) models 142

$\begin{array}{lll}4.4 & \text { Bootstrapping } & 142\end{array}$

4.4.1 Bootstrapping to reduce bias 142

4.5 Results of a simulation: estimation by least squares, first-order bias correction and recursive mean adjustment 145

$\begin{array}{lll}4.6 & \text { Illustrations } & 147\end{array}$

4.6.1 An AR(1) model for US five-year T-bond rate 147

4.6.2 An AR(2) model for US GNP 149

$\begin{array}{lll}4.7 \text { Concluding remarks } & 150\end{array}$

$\begin{array}{ll}\text { Questions } & 151\end{array}$

4.8 Appendix: First-order bias in the constant and linear trend cases 155

5 Confidence Intervals in AR models 158

5.1 Confidence intervals and hypothesis testing 160

$\begin{array}{ll}\text { 5.1.1 Confidence intervals } & 160\end{array}$ 
5.1.2 The link with hypothesis testing 162

$\begin{array}{ll}5.2 \text { The quantile function } & 164\end{array}$

$\begin{array}{lll}\text { 5.2.1 Constant quantiles } & 164\end{array}$

5.2.2 Nonconstancy of the quantiles 165

5.2.3 Complications in the AR case 165

5.2.3.i Simulation of the LS quantiles 166

$\begin{array}{ll}\text { 5.2.3.ii Empirical example: an AR(2) model for US } & \\ \text { GNP } & 167\end{array}$

5.3 Constructing confidence intervals from median unbiased $\begin{array}{ll}\text { estimation } & 169\end{array}$

5.3.1 Inverse mapping and median unbiased estimation $\quad 169$

5.3.2 Confidence intervals based on median unbiased $\begin{array}{ll}\text { estimation } & 173\end{array}$

5.3.3 Extension of the median unbiased method to general $\mathrm{AR}(\mathrm{p})$ models $\quad 175$

5.4 Quantiles using bias adjusted estimators 175

$\begin{array}{lll}\text { 5.4.1 Quantiles } & 175\end{array}$

$\begin{array}{lll}5.4 .2 & \text { Coverage probabilities } & 177\end{array}$

$\begin{array}{lll}5.4 .3 & \text { Section summary } & 178\end{array}$

$\begin{array}{lll}5.5 & \text { Bootstrap confidence intervals } & 179\end{array}$

$\begin{array}{lll}\text { 5.5.1 Bootstrap confidence intervals } & 179\end{array}$

5.5.1.i The bootstrap percentile-t confidence interval 179

5.5.1.ii The grid-bootstrap percentile-t confidence interval 182

$\begin{array}{ll}5.6 \text { Concluding remarks } & 184\end{array}$

Questions 186

6 Dickey-Fuller and Related Tests 189

$\begin{array}{lll}6.1 & \text { The basic set-up } & 190\end{array}$

6.1.1 An AR(1) process 190

6.1.1.i Back-substitution 190

6.1.1.ii Variances 192

6.1.1.iii Weakly dependent errors 193

$\begin{array}{lll}\text { 6.1.2 The LS estimator } & 195\end{array}$

6.1.3 Higher-order AR models 197

6.1.4 Properties of the LS estimator, stationary AR(p) case 199

6.2 Near-unit root case; simulated distribution of test statistics 200

6.3 DF tests for a unit root 203

6.3.1 First steps: formulation and interpretation of the maintained regression 203

$\begin{array}{lll}\text { 6.3.2 Three models } & 205\end{array}$

6.3.3 Limiting distributions of $\hat{\delta}$ and $\hat{\tau}$ test statistics 207 
6.3.4 Obtaining similar tests

6.3.4.i Similarity and invariance in error dynamics/common factor approach

6.3.4.ii Similarity and invariance in the direct (DF) specification

209

6.3.5 Continuous record asymptotics

6.3.6 The long-run variance as a nuisance parameter 212

6.3.7 Joint (F-type) tests in the DF representation 214

6.3.8 Critical values: response surface approach 215

$\begin{array}{lll}6.4 & \text { Size and power } & 217\end{array}$

$\begin{array}{ll}6.5 \text { Nonlinear trends } & 220\end{array}$

6.6 Exploiting the forward and reverse realisations 221

6.6.1 DF-max tests (Leybourne, 1995) 221

6.6.2 Weighted symmetric tests 223

6.7 Non-iid errors and the distribution of DF test statistics 226

$\begin{array}{lll}\text { 6.7.1 Departures from iid errors } & 227\end{array}$

6.7.1.i Distinguishing variances 227

6.7.1.ii Effects on the limit distributions 227

6.7.1.iii Expectations of the limit distributions 229

6.7.1.iv Effect of non-iid errors on the size of the tests 229

$\begin{array}{lll}6.7 .2 & \text { Illustrations } & 231\end{array}$

6.7.2.i MA(1) errors $\quad 231$

6.7.2.ii $\operatorname{AR}(1)$ errors $\quad 232$

6.7.2.iii Effect of non-iid errors on the size of DF tests 233

6.8 Phillips-Perron (PP) semi-parametric unit root test statistics 236

6.8.1 Adjusting the standard test statistics to obtain the same limit distribution 238

6.8.2 Estimation of the variances 239

6.8.2.i The unconditional variance, $\sigma_{\mathrm{z}}^{2} \quad 239$

6.8.2.ii Estimating the long-run variance 240

6.8.3 Modified Z tests 243

6.8.4 Simulation results 244

6.8.4.i PP tests, $\mathrm{Z} \hat{\rho}_{\mu}$ and $\mathrm{Z} \hat{\tau}_{\mu}$, and modified PP tests, $\mathrm{MZ} \hat{\rho}_{\mu}$ and $\mathrm{MZ} \hat{\tau}_{\mu} \quad 244$

6.9 Power: a comparison of the ADF, WS and MZ tests 247

6.10 Concluding remarks 249

Questions $\quad 250$

6.11 Appendix: Response surface function 255

7 Improving the Power of Unit Root Tests 260

$\begin{array}{lll}7.1 & \text { A GLS approach } & 262\end{array}$

$\begin{array}{lll}\text { 7.1.1 GLS estimation } & 263\end{array}$ 
7.1.2 Feasible GLS

7.1.2.i Simple examples 265

7.1.3 Approximating an MA process by an AR model 267

7.1.3.i Using the AR version of FGLS 267

7.1.3.ii Using the MA version of FGLS via an AR approximation 268

7.1.3.iii ARMA errors 270

7.2 FGLS unit root tests 272

7.2.1 DF-type tests based on FGLS 272

7.2.2 GZW unit root test (ARMA variation) 272

7.3 Illustration 276

7.3.1 US Unemployment rate 276

7.3.1.i Standard ADF estimation 276

7.3.1.ii PP tests 277

7.3.1.iii FGLS (GZW version) 278

7.4 Tests that are optimal for particular alternatives (point-optimal tests) 279

7.4.1 Likelihood ratio test based on nearly-integrated alternatives 280

7.4.1.i Known deterministic components 280

7.4.1.ii Unknown deterministic components 282

7.4.1.iii A likelihood-based test statistic, with
estimated trend coefficients

7.4.1.iv The power envelope 285

7.4.2 A family of simple-to-compute test statistics 286

7.4.2.i The PT tests 286

7.4.2.ii Estimating $\sigma_{\mathrm{z}, \mathrm{lr}}^{2} \quad 287$

7.4.3 GLS detrending and conditional and unconditional tests 288

7.4.4 Unconditional case: the QT family of test statistics 290

7.4.5 Exploiting the quasi-differencing interpretation 291

7.4.6 ADF tests using QD data 293

7.4.7 Critical values 294

7.4.8 Illustration of a power envelope and tangential power functions 294

7.4.8.i Graphical illustrations 294

7.4.8.ii Power gains? 297

7.4.9 Sensitivity to the initial condition 298

7.4.10 A test statistic almost invariant to the initial condition 300

7.4.11 Weighted test statistics to achieve robustness to the initial condition 303

7.4.11.i Combining test statistics 304

7.4.11.ii Power and the initial condition 304 
7.4.12 Illustration: US industrial production

7.5 Detrending (or demeaning) procedure by recursive mean adjustment

$\begin{array}{ll}7.6 \text { Concluding remarks } & 312\end{array}$

Questions 313

8 Bootstrap Unit Root Tests 319

8.1 Bootstrap schemes with an exact unit root 321

8.1.1 The random inputs to the bootstrap replications 322

8.1.2 A bootstrap approach to unit root tests 323

$\begin{array}{lll}\text { 8.1.3 The AR(1) case } & 323\end{array}$

8.1.3.i The AR(1) case: no constant 324

8.1.3.ii Variations due to different specifications of the deterministic terms 325

8.1.4 Extension to higher-order ADF/AR models 326

8.1.5 Sieve bootstrap unit root test 327

8.1.5.i Chang and Park sieve bootstrap 328

8.1.5.ii Psaradakis bootstrap scheme 333

8.2 Simulation studies of the bootstrap unit root tests 335

8.2.1 Chang and Park 336

$\begin{array}{lll}\text { 8.2.2 Psaradakis } & 336\end{array}$

8.2.2.i Summary of results 337

8.2.2.ii Lag truncation criteria 338

8.2.3 A brief comparison of the methods of Chang and Park and Psaradikis 338

8.2.3.i AIC versus marginal-t as lag selection criteria 339

8.2.3.ii Summary 341

8.2.4 'Asymptotic' simulations $\quad 342$

8.3 Illustration: US unemployment rate 342

$\begin{array}{ll}8.4 \text { Concluding remarks } & 345\end{array}$

Questions 346

9 Lag Selection and Multiple Tests $\quad 348$

$\begin{array}{lll}9.1 & \text { Selection criteria } & 349\end{array}$

9.1.1 ADF set-up: reminder 350

9.1.2 Illustration of the sensitivity of size and power to lag
length selection

9.1.3 Consistency and simulation lag selection criteria 356

9.1.4 Lag selection criteria 358

9.1.4.i Fixed lag 358

9.1.4.ii Choose $\mathrm{k}^{*}$ as a function of $\mathrm{T} \quad 359$

9.1.4.iii Data-dependent rules 359

$\begin{array}{lll}\text { 9.1.5 Simulation results } & 362\end{array}$ 
9.1.5.i MA(1) errors $\quad 363$

9.1.5.ii AR(1) errors 364

9.1.5.iii Lag lengths $\quad 365$

9.2 Multiple tests 367

$\begin{array}{lll}\text { 9.2.1 Test characteristics } & 367\end{array}$

9.2.2 Defining the indicator sets 368

9.2.3 Overall type I error 370

9.2.4 Test power and test dominance $\quad 372$

9.2.4.i Test dependency function 373

9.2.4.ii Test conflict function 373

9.2.5 Illustrations: different test statistics and different lag selection criteria 374

9.2.5.i Illustration 1: a comparison of $\hat{\tau}_{\mu}$ and $\hat{\tau}_{\mu}^{\mathrm{Ws}} \quad 374$

9.2.5.ii Illustration 2: using different lag selection methods 376

$\begin{array}{lll}9.3 & \text { Empirical illustration } & 381\end{array}$

$\begin{array}{lll}9.4 & \text { Concluding remarks } & 382\end{array}$

Questions 383

10 Testing for Two (or More) Unit Roots 385

$\begin{array}{ll}10.1 \text { Preliminaries } & 386\end{array}$

$\begin{array}{lll}10.1 .1 & \mathrm{I}(2) \text { characteristics } & 387\end{array}$

$\begin{array}{ll}\text { 10.1.2 Illustrative series } & 389\end{array}$

10.1.3 Alternatives to I(2) 391

10.1.4 Some factorisations and restrictions 393

10.2 The Hasza-Fuller (HF) decomposition of a lag polynomial 395

10.2.1 Derivation of the HF decomposition 395

10.2.1.i Example 1 397

10.2.1.ii Numerical example (continuation) 397

10.2.1.iii Example $2 \quad 398$

10.3 DF test as a second unit root is approached 398

10.4 Testing the null hypothesis of two unit roots 401

$\begin{array}{ll}\text { 10.4.1 The HF test } & 402\end{array}$

10.4.1.i Direct demeaning 402

10.4.1.ii Initial conditions 404

10.4.2 Critical values for HF F-type tests 405

10.4.3 Sen-Dickey version of the HF test 405

10.4.3.i Double-length regression for the SD
symmetric test statistic

10.4.3.ii SD F-type test, $\mathrm{p}=2 \quad 409$

10.4.3.iii SD F-type test, $\mathrm{p}>2 \quad 410$

10.4.3.iv Deterministic components 410 
10.5 The Dickey-Pantula (DP) approach 412

10.5.1 An extension of the DF procedure 412

10.5.2 Numerical illustration 413

10.5.3 Start from the highest order of integration 414

$\begin{array}{ll}10.6 \text { Power } & 415\end{array}$

10.6.1 Asymptotic local power $\quad 415$

10.6.2 Small sample simulation results 416

10.6.2.i SD comparison of the HF and SD versions of the F test 416

10.6.2.ii Illustrative simulations: F test and DP tests 417

10.7 Illustrations of testing for two unit roots 418

10.7.1 Illustration 1: the stock of US consumer credit 418

10.7.2 Illustration 2: CPI Denmark 424

10.8 Concluding remarks $\quad 428$

Questions 429

11 Tests with Stationarity as the Null Hypothesis 434

11.1 A structural time series model interpretation 436

11.1.1 The local level model 437

11.1.2 The importance of the limits $\quad 440$

11.1.3 The 'fluctuations' testing framework 441

$\begin{array}{ll}11.2 \text { Tests for stationarity } & 442\end{array}$

11.2.1 The KPSS test 442

11.2.2 Modified rescaled range test statistic (MRS) (Lo, 1991) 443

11.2.3 Komogoroff-Smirnoff-type test (KS) (Xiao, 2001) 445

11.2.4 A Durbin-Watson-type test (SBDH) (Choi and Ahn, 1999) 446

11.3 A test with parametric adjustment 448

11.3.1 The Leybourne and McCabe (1994) test 448

11.3.2 The modified Leybourne and McCabe test 450

11.3.3 Data-dependent lag selection for the LBM test(s) 451

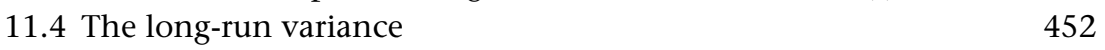

11.4.1 Estimation of the long-run variance 452

11.4.2 Illustrative simulation results $\quad 454$

11.5 An evaluation of stationarity tests 456

11.5.1 Selection of the bandwidth parameter 456

11.5.2 Summary tables of limiting distributions and critical values 458

$\begin{array}{lll}\text { 11.5.3 Empirical size } & 460\end{array}$

11.5.3.i Illustrative simulations 461

11.5.3.ii Looking at the quantiles: comparing
empirical distribution functions 
11.5.4 The power of tests for stationarity against the unit root alternative

11.5.4.i Power against a fixed alternative

11.5.4.ii Power against local alternatives

478

11.6 Illustrations: applications to some US consumer price indices

482

11.6.1 US CPI (aggregate series)

482

11.6.2 US regional consumer prices: using tests of nonstationarity and stationarity in testing for convergence

11.6.2.i Framework for tests

486

11.6.2.ii Consumer prices for two regions of the US

11.7 Concluding remarks

491

Questions

494

12 Combining Tests and Constructing Confidence Intervals

497

12.1 The importance of the initial condition

498

12.2 Problems with stationarity tests for highly correlated series

500

12.3 Confidence intervals revisited

503

12.3.1 Inverting the PT unit root test statistic to obtain a confidence interval

12.3.2 Constructing a confidence interval using DF tests with GLS detrended data

508

12.3.2.i Test inversion $\quad 508$

12.3.2.ii Illustration using time series on US GNP $\quad 511$

12.4 Concluding remarks

Questions

13 Unit Root Tests for Seasonal Data $\quad 519$

$\begin{array}{ll}13.1 \text { Seasonal effects illustrated } & 521\end{array}$

$\begin{array}{ll}\text { 13.2 Seasonal 'split' growth rates } & 524\end{array}$

13.3 The spectral density function and the seasonal frequencies $\quad 525$

13.3.1 Frequencies, periods and cycles 526

$\begin{array}{ll}\text { 13.3.2 Power spectrum and periodogram } & 527\end{array}$

13.3.3 Illustrations (randomising the input) 529

13.3.4 Aliasing (artificial cycles) 532

13.3.5 Seasonal integration from a frequency domain perspective

$\begin{array}{ll}\text { 13.4 Lag operator algebra and seasonal lag polynomials } & 535 \\ \text { 13.4.1 The seasonal operator in terms of L } & 535\end{array}$

13.5 An introduction to seasonal unit root tests: the DHF (1984) test 539

$\begin{array}{lll}\text { 13.5.1 The seasonal DGP } & 539\end{array}$

13.5.1.i No deterministic components $\quad 540$ 
13.5.1.ii Seasonal intercepts $\quad 540$

13.5.1.iii Seasonal deterministic trends $\quad 542$

13.5.2 Limiting distributions $\quad 543$

13.6 HEGY tests $\quad 543$

13.6.1 The HEGY regression $\quad 545$

13.6.2 The constructed variables and the seasonal frequencies 546

13.6.3 The structure of hypothesis tests 547

13.6.3.i Tests for the roots $+1,-1 \quad 547$

13.6.3.ii Tests for unit roots at the harmonic seasonal frequencies, $\lambda_{\mathrm{s}}, \mathrm{s} \neq 0, \mathrm{~s} \neq \mathrm{S} / 2 \quad 547$

13.6.3.iii Overall tests $\quad 548$

13.6.4 The HEGY tests: important special cases 548

13.6.4.i Quarterly data $\quad 548$

13.6.4.ii Monthly data $\quad 550$

13.6.5 Limiting distributions and critical values $\quad 552$

13.6.5.i Monthly case $\quad 553$

13.6.5.ii Quarterly case $\quad 555$

13.6.5.iii Nuisance parameters $\quad 555$

13.6.5.iv Empirical quantiles $\quad 556$

13.6.6 Multiple testing $\quad 558$

$\begin{array}{ll}\text { 13.6.7 Lag augmentation } & 561\end{array}$

13.7 Can the (A)DF test statistics still be used
for seasonal data?

13.8 Improving the power of DHF and HEGY tests 562

13.8.1 Recursive mean adjustment for seasonal unit root tests 563

13.8.2 Improving power with monthly data $\quad 564$

13.8.2.i Systematic sampling $\quad 564$

13.8.2.ii QM-HEGY 564

13.8.2.iii Choice of test statistic for quarterly data $\quad 566$

13.8.2.iv Critical values $\quad 567$

13.8.2.v Illustration: US industrial production $\quad 567$

13.9 Finite sample results, DHF and HEGY 568

13.9.1 Power, initial assessment $\quad 569$

13.9.2 Not all roots present under the null $\quad 570$

13.9.2.i AR(1) DGP $\quad 572$

13.9.2.ii Other DGPs: one cycle and two cycles per year 574

13.9.3 Extension to include RMA versions of

the HEGY and DHF tests 577

$\begin{array}{ll}\text { 13.9.4 Size retention } & 578\end{array}$ 
13.10 Empirical illustrations

582

13.10.1 Illustration 1, quarterly data: employment in US agriculture

582

13.10.1.i A linear trend alternative $\quad 582$

13.10.1.ii A nonlinear trend alternative

586

13.10.2 Illustration 2, monthly data: UK industrial production

587

13.11 Some other developments 590

13.11.1 Periodic models 590

13.11.2 Stationarity as the null hypothesis 592

13.12 Concluding remarks 593

Questions 594

Appendix 1: Random Variables; Order Notation 597

A1.1 Discrete and continuous random variables 597

A1.2 The (cumulative) distribution function, $\mathrm{cdf} \quad 598$

A1.2.1 CDF for discrete random variables 598

A1.2.2 CDF for continuous random variables 599

A1.3 The order notation: 'big' O, 'small' o 602

Appendix 2: The Lag Operator and Lag Polynomials 603

A2.1 The lag operator, L 603

A2.2 The lag polynomial 603

A2.3 Differencing operators 604

A2.4 Roots 605

A2.4.1 Solving for the zeros 605

A2.4.2 Graphical representation of the roots 605

A2.4.3 Roots associated with seasonal frequencies 608

A2.5 The inverse of a lag polynomial and the summation operator 609

A2.5.1 The inverse lag polynomial 609

A2.5.2 The summation operator $\Delta^{-1}$ as an inverse polynomial 610

A2.6 Stability and the roots of the lag polynomial 610

A2.7 Some uses of the lag operator $\quad 612$

A2.7.1 Removing unit roots $\quad 612$

$\begin{array}{lll}\text { A2.7.2 Data filter } & 613\end{array}$

A2.7.3 Summing the lag coefficients 614

A2.7.4 Application to a (deterministic) time trend 615

Questions 615

$\begin{array}{ll}\text { References } & 619\end{array}$

Author Index $\quad 633$

Subject Index 637 


\section{List of Tables}

P.1 Number of citations of key articles on unit roots xxiv

1.1 Contrasting properties of I(0) and I(1) series 26

2.1 Errors of specification 41

2.2 Estimated ARMA models for US GNP (real) 58

$\begin{array}{lll}2.2 \mathrm{a} & \text { ARMA }(3,2) \text { model for } \mathrm{y}_{\mathrm{t}} & 58\end{array}$

$\begin{array}{lll}2.2 \mathrm{~b} & \text { ARMA }(2,2) \text { model for } \Delta \mathrm{y}_{\mathrm{t}} & 58\end{array}$

2.3 Roots of the polynomials of the ARMA models 58

2.3a ARMA $(3,2)$ model for $y_{t} \quad 58$

$\begin{array}{lll}2.3 \mathrm{~b} & \text { ARMA }(2,2) \text { model for } \Delta \mathrm{y}_{\mathrm{t}} & 58\end{array}$

3.1 Finite sample critical values for conditional and unconditional LR-type test statistics 109

3.2 LS, CML and ML: illustrative simulation results, MA(1) errors, $\mathrm{T}=100 \quad 110$

3.3 ARMA models for UK car production, coefficient estimates 112

$\begin{array}{lll}3.4 & \text { Test statistics for a unit root, car production data }\end{array}$

$4.1 \quad$ First-order least squares bias: $\lim _{\mathrm{T} \rightarrow \infty} \mathrm{T}\left[\mathrm{E}\left(\hat{\phi}_{\mathrm{i}}-\phi_{\mathrm{i}}\right)\right] \quad 126$

4.1a Constant included in regression 126

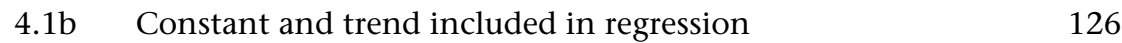

$\begin{array}{lll}4.2 & \text { Total bias of LS estimators and fixed points } & 126\end{array}$

4.2a Constant included in regression $\quad 126$

4.2b Constant and trend included in regression 126

4.3 A summary of the abbreviations used in the following

4.4 Bias correction in an AR(1) model 146

4.5 LS and bias adjusted estimates of an AR(2) model for US

4.6 LS and bias adjusted estimates of an AR(2) model for US GNP 150

4.7 Roots for the zero bias case: constant included in regression 153

$\begin{array}{ll}5.1 & \text { Quantiles to obtain a median unbiased estimator } \\ 5.2 & \text { Simulated }\end{array}$

$\begin{array}{ll}5.2 & \text { Simulated coverage probabilities } \\ \end{array}$ 
6.1 Percentage of times that $t_{\rho}<-1.645$

203

6.2 Summary of simple maintained regressions: error dynamics/common factor approach

206

6.3 Summary of maintained regressions: DF representations

207

6.4 Null hypothesis for DF joint F-type tests

215

6.5 Illustration of response surface coefficients

216

6.6 Illustrative size and power comparisons of DF-type tests

218

6.6a MA(1) error structure: $z_{t}=\left(1+\theta_{1} L\right) \varepsilon_{t}$

218

6.6b AR(1) error structure: $\left(1-\varphi_{1} \mathrm{~L}\right) \mathrm{z}_{\mathrm{t}}=\varepsilon_{\mathrm{t}}$

219

6.7 Critical values of the DF-max tests, $\hat{\tau}_{\mu}^{\max }$ and $\hat{\tau}_{\beta}^{\max }$

223

6.8 Effect of non-iid errors on means of limit distribution of test statistics

6.9 Effect on (asymptotic) size of DF tests with non-iid errors

6.10a Effect of MA(1) errors on the size of PP-type tests, 5\% nominal size

6.10b Effect on AR(1) errors on the size of PP-type tests, 5\% nominal size

6.11 Illustrative size and power comparisons of DF-type tests 248

$\begin{array}{lll}6.11 \mathrm{a} & \mathrm{MA}(1) \text { error structure } & 248\end{array}$

$\begin{array}{lll}6.11 b & \mathrm{AR}(1) \text { error structure } & 248\end{array}$

$\begin{array}{lll}6.12 & \text { Response surface coefficients } & 257\end{array}$

7.1 Summary of GLS matrices, general and special cases 264

7.2 Size and power comparisons: CGLS and ML test statistics, $\mathrm{AR}(1)$ error structure

7.3 Estimation results for US unemployment, Nelson and Plosser data

7.4 Summary of unit root test values for US unemployment data

7.5 Critical values (fixed initial condition)

7.6 Critical values (initial condition: drawn from unconditional distribution)

$\begin{array}{lll}7.7 & \text { Critical values for } \hat{\mathrm{Q}}^{(\mathrm{i})}(\mathrm{g}, \lambda) & 303\end{array}$

$\begin{array}{lll}7.8 & \text { Critical values for } \hat{\tau}_{i}^{\mathrm{DFG}}, \hat{\tau}_{\mathrm{i}}^{\mathrm{DFQ}} & 305\end{array}$

$\begin{array}{lll}7.9 & \text { Critical values for } \hat{\tau}_{\mu}^{\text {rma }} \text { and } \hat{\tau}_{\beta}^{\text {rma }} & 311\end{array}$

$\begin{array}{lll}7.10 & \text { Estimation results for US unemployment } & 314\end{array}$

7.11 Summary of unit root test values for US unemployment data

8.1 Simulated size and power of the Chang and Park ADF tests 
8.2 Simulated size $(\rho=1)$ and power $(\rho=0.9)$ of Psaradakis bootstrap tests for $5 \%$ nominal size, $\mathrm{T}=100 ; \theta_{1}=-0.8$ throughout

8.3 Comparison of bootstrapping procedures

8.3a Simulated size: $\theta_{1}=0$ and $\rho=1$; simulated power: $\theta_{1}=0$ and $\rho=0.95, \theta_{1}=0$ and $\rho=0.9$

8.3b Simulated size: $\theta_{1}=-0.4$ and $\rho=1$; simulated power: $\theta_{1}=-0.4$ and $\rho=0.95, \theta_{1}=-0.4$ and $\rho=0.9$

8.3c Simulated size: $\theta=-0.8$ and $\rho=1$; simulated power: $\theta_{1}=-0.8$ and $\rho=0.95, \theta_{1}=-0.8$ and $\rho=0.9$

8.4 'Aysmptotic' size: $\theta_{1}=-0.8$ and $\rho=1$

8.5 ML estimation of $\operatorname{ARIMA}(2,0,2)$ for US unemployment rate

8.6 Test statistics for US unemployment rate

9.1 MA(1) errors: empirical size and power of $\hat{\tau}_{\mu}$ using different lag selection criteria

9.2 AR(1) errors: size and power of $\hat{\tau}_{\mu}$, different lag selection criteria

9.3 Intersection of sets using different lag selection criteria, \% same choice, MA(1)

9.4 Intersection of sets using different lag selection criteria, \% same choice, $\operatorname{AR}(1)$

9.5 Joint probabilities for two test statistics

9.6 Probabilities under independence of tests given $\mathrm{H}_{0}$

9.7 Illustrative probabilities if tests are distributed as joint normal, $\alpha=0.05$, with dependency indicated by $\eta$

10.1 A taxonomy of possibilities in the two root case

10.2 Critical values for HF F-type tests

10.3 Empirical power of tests for two unit roots; data directly demeaned assuming a constant mean

10.4 Empirical power of tests for two unit roots; data directly demeaned by a constant and linear trend

10.5 Empirical power of tests for two unit roots; data directly demeaned by a constant, linear trend and a quadratic trend

10.6 Number of unit roots; estimation details for log consumer credit, US

10.7 Number of unit roots; estimation details for log of CPI, Denmark

10.8 Dependent and explanatory variables in the simple symmetric test of Sen and Dickey 
11.1 Limiting distributions of test statistics for stationarity

11.2 Quantiles of null distributions for stationary tests (critical values)

11.3 Effect of lag selection on quantiles of $\operatorname{LBM}^{(\mu)}$

11.4 Stationarity tests: empirical size for 5\% nominal size AR(1) errors

11.5 Stationarity tests: empirical size for 5\% nominal size, MA(1) errors

11.6a LBM tests, US CPI (logs)

$11.6 \mathrm{~b}$ Stationarity tests, US CPI (logs)

11.7 Long-run variance estimates and bandwidth parameters

11.8 Unit roots tests on US regional CPIs; (log) levels, N-E and W

11.9 US regional inflation contrast: $\operatorname{LBM}^{(\mu)}$ tests for stationarity

11.10 US regional inflation contrast: tests for stationarity

12.1 Sensitivity of empirical size to the initial condition

12.2 Upper quantiles of unit root test statistics when used for staionarity

12.3 The roles of different values of $\mathrm{c}$ and $\rho$

12.4 $\mathrm{H}_{0}: \rho=\rho^{*}$ against $\mathrm{H}_{\mathrm{A}}: \rho=\bar{\rho}$ or, equivalently, $\mathrm{c}=\mathrm{c}^{*}$ against $\mathrm{C}=\overline{\mathrm{C}}$

13.1 Calculation of seasonal 'split' growth rates:

$$
\Delta_{1} \mathrm{y}_{\mathrm{n}, \mathrm{s}}=\mathrm{y}_{\mathrm{n}, \mathrm{s}}-\mathrm{y}_{\mathrm{n}, \mathrm{s}-1}
$$

13.2 Aliased frequencies: monthly data sampled at quarterly intervals

13.3 Seasonal test statistics distinguished by mean and trend components

13.5 Seasonal frequencies, periods and roots: the quarterly case 549

13.6 Constructed variables and seasonal frequencies: the quarterly case

13.7 Hypothesis tests: the quarterly case 549

13.8 Seasonal frequencies, periods and roots: the monthly case 552

13.9 Constructed variables and seasonal frequencies: the monthly case

13.10 Hypothesis tests: the monthly case 553

13.11 Limiting null distributions of HEGY test statistics 554

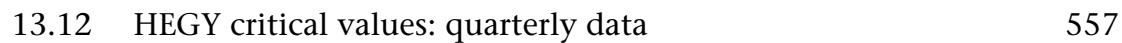

13.13 HEGY critical values: monthly data 559

13.14 Matrix of estimated pairwise probabilities (monthly tests) 561 
13.15 Some critical values for QM-HEGY, 5\% tests (4\% quarterly, $1 \%$ monthly)

13.16 Summary of results for US industrial production 568

$\begin{array}{lll}13.17 & \text { Size and power of tests } & 578\end{array}$

13.18 Size of tests: AR(1) errors $\quad 580$

13.19 Size of tests: MA(4) errors 581

13.20 Average lags for AR(1) errors and MA(4) errors 582

13.21 Test statistics for unit roots for US agricultural employment 585

13.22 Test statistics for unit roots for UK industrial production (monthly) 589

13.23 Constructed variables and seasonal frequencies for the weekly case

13.24 The structure of hypotheses: the weekly case 


\section{List of Figures}

1.1 Sample paths of a binomial random walk 2

$\begin{array}{ll}1.2 & \text { Distribution function of visits to the origin }\end{array}$

$\begin{array}{lll}1.3 & \text { Sample paths of a Gaussian random walk } & 13\end{array}$

$\begin{array}{lll}1.4 & \text { Sample paths of asymmetric binomial random walks } & 14\end{array}$

$\begin{array}{lll}1.5 & \text { Sample paths of drifted symmetric binomial random walks } & 15\end{array}$

$\begin{array}{lll}1.6 & \text { Exchange rate (daily), SWFR:£ } & 15\end{array}$

$\begin{array}{lll}1.7 & \text { Scatter graph of daily, SWFR:£ } & 16\end{array}$

$\begin{array}{lll}1.8 & \text { Gaussian random walk as time divisions approach zero } & 17\end{array}$

2.1 AC functions for residuals of detrended series 44

2.2a Simulated spectral density function, $\mathrm{T}=100 \quad 45$

2.2b Simulated spectral density function, $\mathrm{T}=200 \quad 45$

$2.3 \quad$ Power spectrum of over-differenced series 47

$2.4 \quad$ US GNP (quarterly, s.a.) 57

2.5 Impulse responses based on $\operatorname{ARMA}(2,2)$ model 59

2.6 Estimates of $\mathrm{G}(1)$ and variance ratio from $\mathrm{AR}(\mathrm{k})$ models $\quad 60$

$\begin{array}{lll}2.7 & \text { Simulated density function of } \mathrm{R}^{2} & 63\end{array}$

$\begin{array}{lll}2.8 & \text { Simulated density function of } \mathrm{t}_{\beta_{2}} & 63\end{array}$

$2.9 \quad$ Measures of persistence for an MA(1) process 67

$\begin{array}{lll}3.1 & \text { UK car production (logs, p.a., s.a.) } & 111\end{array}$

$\begin{array}{lll}3.2 & \text { Permanent and transitory car production (logs) }\end{array}$

$\begin{array}{lll}4.1 & \text { Bias functions of estimators } & 131\end{array}$

$\begin{array}{ll}4.2 & \text { RMSE functions of estimators } \\ 4.3 & 147\end{array}$

$\begin{array}{lll}4.3 & \text { US five-year T-bond rate } & 148\end{array}$

$\begin{array}{ll}4.4 & 149\end{array}$

$5.1 \quad 5 \%$ and 10\% quantiles and t-function 166

$\begin{array}{ll}5.2 & 167\end{array}$

5.3 Quantiles for LS estimates: US GNP 168

$\begin{array}{lll}5.4 & 172\end{array}$

$\begin{array}{lll}5.5 & 172\end{array}$

$\begin{array}{lll}5.6 & 90 \% \text { confidence interval } & 174\end{array}$

$\begin{array}{lll}5.7 & 5 \% \text { quantiles for different estimators } & 176\end{array}$

$\begin{array}{lll}5.8 & 95 \% \text { quantiles for different estimators } & 177\end{array}$ 
$\begin{array}{lll}\text { 5.9a } & \text { Simulated cumulative distribution function } & 181\end{array}$

5.9b Simulated inverse cumulative distribution function $\quad 181$

$\begin{array}{lll}5.10 & 185\end{array}$

$\begin{array}{ll}5.11 & 187\end{array}$

6.1a Distribution of $t_{\rho}$ (no constant in estimated model) 201

6.1b Distribution of $t_{\rho}$ (constant in estimated model) 202

6.1c Distribution of $t_{\rho}$ (constant and trend in estimated model) 202

$\begin{array}{lll}6.2 & \text { Distribution of } t_{\rho} \text { with drift in DGP } & 211\end{array}$

6.3 Ratio of variances: long-run/unconditional (MA(1) errors) 232

6.4 Ratio of variances: long-run/unconditional (AR(1) errors) 233

6.5a Distribution of $\hat{\tau}$ with MA(1) errors 235

6.5b Distribution of $\hat{\tau}_{\mu}$ with MA(1) errors 235

6.5c Distribution of $\hat{\tau}_{\beta}$ with MA(1) errors 236

6.6a Distribution of $\hat{\tau}$ with AR(1) errors 236

$\begin{array}{ll}\text { 6.6b Distribution of } \hat{\tau}_{\mu} \text { with AR(1) errors } & 237\end{array}$

6.6c Distribution of $\hat{\tau}_{\beta}$ with $\operatorname{AR}(1)$ errors 237

7.1 US unemployment rate (Nelson and Plosser series) 277

$\begin{array}{lll}7.2 & \text { Variation in 5\% critical values for test statistics } & 296\end{array}$

$\begin{array}{lll}7.3 & \text { Illustration of power envelope for } \rho_{\mathrm{T}, \mu}(\mathrm{c}) & 296\end{array}$

$\begin{array}{lll}7.4 & \text { Comparison of power envelopes } & 297\end{array}$

7.5 Power as scale of initial observation varies, $\pi(\kappa \mid \rho)$, constant in estimated model 299

7.6 Power as initial observation varies, $\pi(\kappa \mid \rho)$, trend in
estimated model

$\begin{array}{lll}7.7 & \text { Power comparison, } \rho=0.95 & 305\end{array}$

$\begin{array}{lll}7.8 & \text { Power comparison: the weighted tests } 306\end{array}$

$\begin{array}{lll}7.9 & \text { US Industrial production (logs, p.a., s.a.) } 307\end{array}$

$\begin{array}{lll}7.10 \mathrm{a} & \text { Estimated scaled residuals } \hat{\xi}_{\mathrm{c}} & 308\end{array}$

$\begin{array}{lll}7.10 b & \text { Estimated weights } \hat{\alpha} & 308\end{array}$

$\begin{array}{lll}7.11 \mathrm{a} & \mathrm{DF} \text { and GLSC unit root test } & 308\end{array}$

$\begin{array}{lll}7.11 b & \text { Weighted unit root test } & 308\end{array}$

8.1 US unemployment rate (monthly data) 343

9.1 MA (1) errors: size and power, $\hat{\delta}_{\mu} \quad 352$

$\begin{array}{lll}\text { 9.2 } & \text { MA(1) errors: size and power, } \hat{\tau}_{\mu} & 353\end{array}$

9.3 MA(1) errors: relative frequency of lags chosen by AIC 353

$\begin{array}{lll}9.4 & \mathrm{AR}(1) \text { errors: size and power, } \hat{\delta}_{\mu} & 355\end{array}$

$\begin{array}{lll}9.5 & \mathrm{AR}(1) \text { errors: size and power, } \hat{\tau}_{\mu} & 355\end{array}$ 
9.6 AR(1) errors: relative frequency of lag chosen by AIC 356

$\begin{array}{lll}\text { 9.7a } & \text { Bivariate normal with } \eta=0.75 & 371\end{array}$

9.7b Probability of conflict, two tests, bivariate normal 372

$\begin{array}{lll}9.8 & \text { Power functions for } \hat{\tau}_{\mu} \text { and } \hat{\tau}_{\mu}^{\mathrm{Ws}} & 374\end{array}$

$\begin{array}{lll}9.9 & \text { Conditional test dependency functions } & 375\end{array}$

$\begin{array}{lll}9.10 & 376\end{array}$

9.11 Power of $\hat{\tau}_{\mu}$ using G-t-S and MAIC 377

9.12 Conditional test dependencies, G-t-S and MAIC 378

9.13 Unconditional test conflict $\hat{\tau}_{\mu}$ with G-t-S and MAIC 379

$\begin{array}{lll}9.14 & \text { Power of } \hat{\tau}_{\mu} \text { using G-t-S and MAIC } & 379\end{array}$

9.15 Conditional test dependencies $\hat{\tau}_{\mu}$ with G-t-S and MAIC 380

9.16 Unconditional test conflict $\hat{\tau}_{\mu}$ with G-t-S and MAIC 380

$\begin{array}{lll}9.17 & \text { US (log) wheat production } & 381\end{array}$

9.18 The impact of different lag lengths 382

10.1 Simulated $\mathrm{I}(\mathrm{d})$ series, $\mathrm{d}=0,1,2,3 \quad 389$

$\begin{array}{lll}10.2 \mathrm{a} & 390\end{array}$

$\begin{array}{lll}10.2 b & & 390\end{array}$

$\begin{array}{lll}10.3 \mathrm{a} & 391\end{array}$

10.3b US consumer credit (logs) 391

10.4a Empirical size of DF $\hat{\tau}_{\mu}$ lower tail 399

10.4b Empirical size of DF $\hat{\tau}_{\mu}$ upper tail 400

10.5a Empirical size of DF $\hat{\tau}_{\beta}$ lower tail 400

10.5b Empirical size of DF $\hat{\tau}_{\beta}$ upper tail 401

10.6a US Consumer credit, actual and trends (logs) 421

10.6b Residuals from trends, US credit 421

10.6c US credit, monthly growth rate and trend 422

10.6d Residuals for linear trend for growth rate 422

10.7a Denmark CPI (logs), actual and trends 425

10.7b Residuals from trends, Denmark CPI 426

10.7c Denmark CPI, annual inflation rate and trend 426

10.7d Residuals from linear trend for growth rate 427

$11.1 \quad$ Bartlett and quadratic spectral kernals 453

11.2 Estimators of long-run variance: rmse, $\operatorname{AR}(1)$

11.3 QS, BW and QS (CAB) estimators: rmse, AR(1) 456

11.4 Estimators of long-run variance: rmse, $\mathrm{MA}(1) \quad 457$

11.5 Comparison by bandwidth criteria: rmse, MA(1) 457

11.6a KS ${ }^{\mu}$, empirical size for AR(1) errors: 4 kernels 464

11.6b LBM $^{\mu}$, empirical size for AR(1) errors 464

11.7 Best of each test, empirical size for AR(1) errors 465

11.8a KPSS $^{\mu}$, empirical size for MA(1) errors: 4 kernels 466 
11.8b LBM $^{\mu}$, empirical size for MA(1) errors 467

11.9 Best of each test, empirical size for MA(1) errors 467

11.10 EDFs for $\operatorname{KPSS}^{(\mu)}$ and $\operatorname{LBM}^{(\mu)} \quad 468$

$\begin{array}{lll}11.11 & \mathrm{EDFs} \text { for } \mathrm{KPSS}^{(\mu)}, \operatorname{AR}(1) \text { errors } & 469\end{array}$

$\begin{array}{lll}11.12 & \mathrm{EDFs} \text { for } \mathrm{LBM}^{(\mu)}, \operatorname{AR}(1) \text { errors } & 469\end{array}$

11.13 EDFs for $\operatorname{KPSS}^{(\mu)}, \operatorname{MA}(1)$ errors $\quad 470$

$\begin{array}{lll}11.14 & \text { EDFs for } \operatorname{LBM}^{(\mu)}, \operatorname{MA}(1) \text { errors } & 471\end{array}$

11.15a Power of test statistics in standard versions $(\mathrm{T}=100) \quad 473$

$11.15 \mathrm{~b}$ Size-adjusted power of test statistics $(\mathrm{T}=100$, semi-parametric tests use $\left.\mathrm{m}^{(\mathrm{qs})}(4)\right)$

11.15c Size-adjusted power of test statistics $(\mathrm{T}=100$, semi-parametric tests use $\mathrm{m}_{\mathrm{cab}}^{(\mathrm{qs})}$ )

11.15d Size-adjusted power of test statistics $(\mathrm{T}=100$, semi-parametric tests use $\left.\mathrm{m}^{(\mathrm{bw})}(4)\right)$

11.15e Size-adjusted power of test statistics $(\mathrm{T}=100$, semi-parametric tests use $\mathrm{m}_{\mathrm{cab}}^{(\mathrm{bw})}$ )

11.15f Size-adjusted power of LBM test statistics $(\mathrm{T}=100) \quad 475$

11.16a Best power combinations $(\mathrm{T}=100) \quad 476$

11.16b Power comparison with best-size combinations $(\mathrm{T}=100) \quad 476$

11.17a Size-adjusted power, AR(1) DGP $(\mathrm{T}=500$, semi-parametric tests use $\left.\mathrm{m}^{(\mathrm{qs})}(4)\right)$

11.17b Best power and size, AR(1) DGP $(\mathrm{T}=100)$

11.18a Best power combinations $(\mathrm{T}=500) \quad 479$

11.18b Power comparison with best size combinations $(\mathrm{T}=500) \quad 479$

11.19a Size adjusted power, AR(1) DGP $(\mathrm{T}=500$, semi-parametric tests use $\left.\mathrm{m}^{(\mathrm{qs})}(4)\right) \quad 480$

11.19b Best power and size, AR(1) DGP $(\mathrm{T}=500)$

11.19c Best power and size, $\operatorname{AR}(1)$ DGP $(\mathrm{T}=500$, semi-parametric tests use $\left.\mathrm{m}_{\mathrm{cab}}^{(\mathrm{bw})}(4)\right)$

11.20 US CPI and linear trend (logs) 483

11.21 US CPI inflation rate 483

$\begin{array}{lll}11.22 & \text { US regional CPIs (logs) } & 488\end{array}$

11.23 CPI contrast $(\log ) \quad 488$

$\begin{array}{lll}11.24 & \text { Regional CPI inflation rates } & 489\end{array}$

$\begin{array}{lll}11.25 & \text { Contrast of inflation rates } & 489\end{array}$

$12.190 \%$ confidence interval using QD data: US GNP 514

12.2 90\% confidence interval, QD data, with c(L): US GNP 515

13.1a Consumers' expenditure (UK) 522

13.1b Consumers' expenditure: seasonal component 522

13.2a Consumers' expenditure (logs) 523 
13.2b Consumers' expenditure (logs): seasonal component

13.3 Consumers' expenditure: DV seasonal component

13.4 Consumers' expenditure

13.5 Expenditure on restaurants and hotels (UK)

13.6 The periodogram for a single frequency

13.7a Periodogram for periods of 12 and 120

13.7b Periodogram for periods of 4 and 120

13.8a Detrended expenditure on restaurants and hotels

13.8b Periodogram for levels

13.9a Quarterly growth rate

$13.9 \mathrm{~b}$ Periodogram for growth rate

13.10 Aliasing of monthly cycles when sampled quarterly

13.11a Periodogram for $\Delta_{4} y_{t}=\varepsilon_{t}$

13.11b Seasonal splits for $\Delta_{4} y_{t}=\varepsilon_{t}$

13.12a Periodograms for $(1+\mathrm{L}) \mathrm{y}_{\mathrm{t}}=\varepsilon_{\mathrm{t}}$ and $\left(1+\mathrm{L}^{2}\right) \mathrm{y}_{\mathrm{t}}=\varepsilon_{\mathrm{t}} \quad 538$

13.12b Seasonal splits for $\mathrm{y}_{\mathrm{t}}=-\mathrm{y}_{\mathrm{t}-1}+\varepsilon_{\mathrm{t}}$

13.12c Seasonal splits for $y_{t}=-y_{t-2}+\varepsilon_{t} \quad 539$

13.13 The monthly, seasonal frequencies $\lambda_{j}$

13.14a Simulated data for $\Delta_{12} y_{t}=\varepsilon_{t}$

13.14b Periodogram for $\Delta_{12} \mathrm{y}_{\mathrm{t}}=\varepsilon_{\mathrm{t}}$

13.15a Power of DFH $\hat{\tau}_{S, S \mu}$ and HEGY F $F_{A l l}$ tests, no lags 571

$13.15 \mathrm{~b}$ Power of DFH $\hat{\tau}_{S, S \mu}$ and HEGY $\mathrm{F}_{\mathrm{All}}$ tests, 4 lags 571

13.16a Power of tests with RW(1) DGP 573

13.16b EDFs for $\hat{\tau}_{S, S \mu}$ with RW(1) DGP 573

13.17a Power of tests with Nyquist DGP

13.17b EDFs for $\hat{\tau}_{S, S \mu}$ with Nyquist DGP $\quad 575$

13.18a Power of tests with seasonal harmonic DGP 576

13.18b EDFs for $\hat{\tau}_{S, S \mu}$ with seasonal harmonic DGP 576

13.19 Power of DFH $\hat{\tau}_{S, S \mu}$ and HEGY $\mathrm{F}_{\mathrm{All}, \mathrm{S} \mu} \quad 579$

13.20 Power of DFH $\hat{\tau}_{S, S \mu, S \beta}$ and HEGY $\mathrm{F}_{\mathrm{All}, \mathrm{S} \mu, \mathrm{S} \beta} \quad 579$

13.21 US agricultural employment 583

13.22 Seasonal split growth rates 584

13.23 Periodogram for US agricultural employment 584

13.24 UK Index of Industrial Production (logs) n.s.a. $\quad 587$

13.25 Periodogram for UK IIP $(\log )$ n.s.a. 588

A1.1 Binomial distribution, pmf and cdf 600

A1.2 Standard normal distribution, pdf and cdf 602

A2.1a Finding the roots of $\phi(\mathrm{z}) \quad 606$

A2.1b $\phi(\mathrm{z})$ with complex roots 607 


\section{Symbols and Abbreviations}

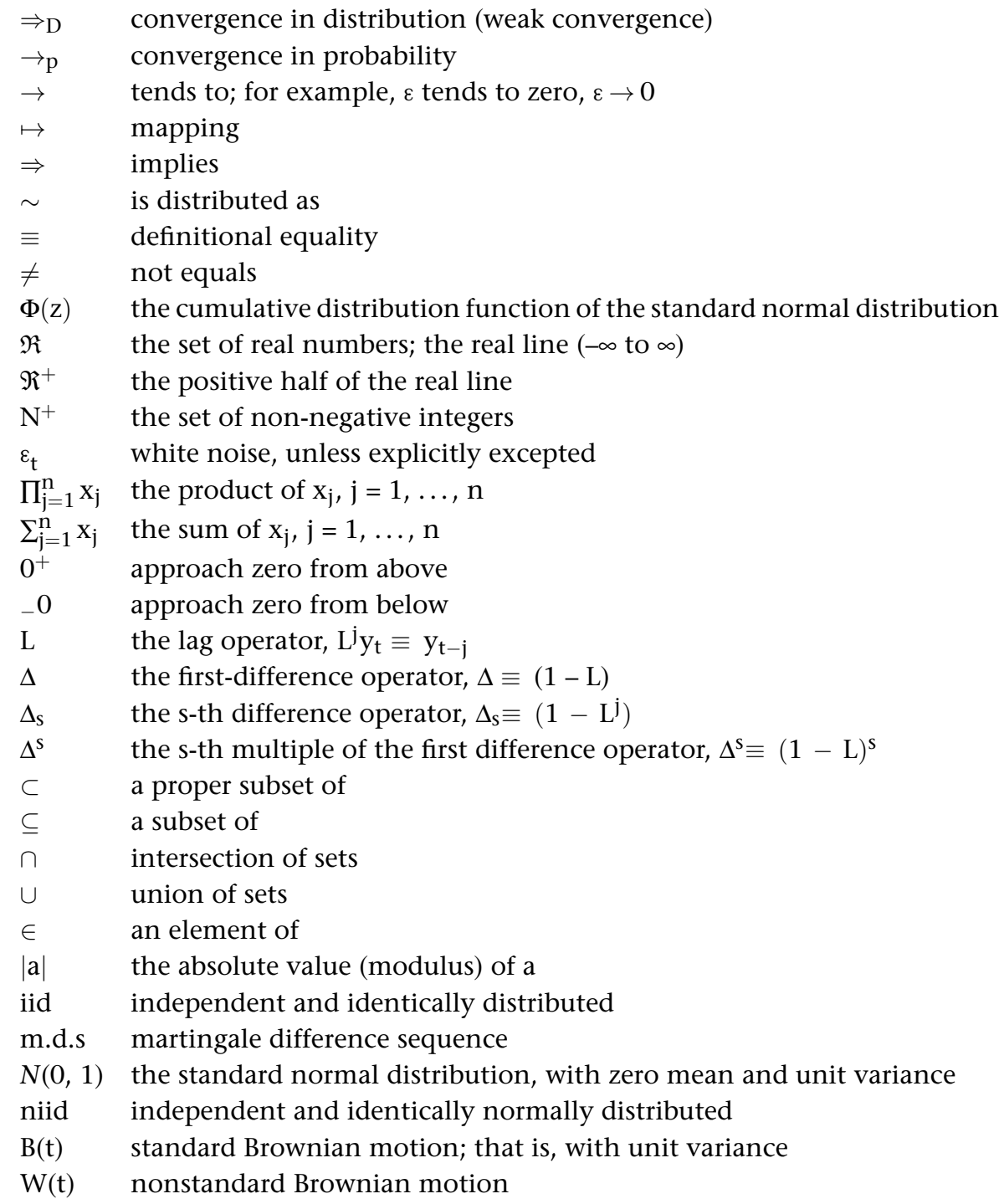




\section{Preface}

The purpose of this book is to provide a review and critical assessment of some key procedures related in one way or another to the problem of testing for a unit root in a stochastic process. As is now well known, the presence of a unit root implies a form of nonstationarity that is considered to be relevant for economic time series, so that a non-standard inferential and distributional framework is required.

The research and literature on this topic has grown almost exponentially since Nelson and Plosser's seminal article published in 1982. Therein they applied the framework due to Dickey (1976) and Fuller (1976) to testing for a unit root in a number of macroeconomic time series. Subsequent key articles by Dickey and Fuller (DF) $(1979,1981)$ developed some aspects of the initial testing framework. The basic set-up for a DF unit root test is now familiar enough, being taught in most intermediate, if not introductory, courses in econometrics; however, the underlying distribution theory is somewhat more advanced, and the many complications that have arisen in practice has meant the development of a voluminous literature that, because of its extent, is difficult to comprehend, especially for the non-specialist. Indeed, it is probably the case that a simple survey of the field of methods and applications is virtually infeasible; indeed, the topic is so extensive that even some 20 years ago Diebold and Nerlove (1990) noted the scale of the literature on this topic.

The articles on unit root tests are amongst the most cited in economics and econometrics and have clearly influenced the direction of economic research at a much wider level than simply testing for a unit root. A citation summary for articles based on univariate processes is presented in Table P.1. The numbers shown here clearly indicate that there has been a sustained interest in the topic over the last 30 years or so and, looking at the wider influence, the unit root literature led to the concept of cointegration and to some of the most cited of econometric articles, including Engle and Granger (1987), Johansen (1988, 1991) and Johansen and Juselius (1990) (see the note to Table P.1).

The appropriate prerequisites for this book include some knowledge of econometric theory at an intermediate or graduate level as, for example, in Davidson (2000), Davidson and Mackinnon (2004) or Mittlehammer et al. (2000), and, possibly, with some additional directed study, as in good introductory books such as Gujarati (2006), Dougherty (2007), Ramanathan (2002) and Stock and Watson (2007). It would also be helpful to have had an introduction to the 
Table P.1 Number of citations of key articles on unit roots.

\begin{tabular}{lrc}
\hline Author(s) & \multicolumn{1}{c}{ Number of citations } \\
\hline Dickey and Fuller (1979) & 1 & 7,601 \\
Phillips and Perron (1988) & 2 & 4,785 \\
Dickey and Fuller (1981) & 3 & 4,676 \\
Perron (1989) & 4 & 3,371 \\
Kwiatkowski, Phillips, Schmidt, Shin (1992) & 5 & 3,280 \\
Nelson and Plosser (1982) & 6 & 3,035 \\
Phillips (1987a) & 7 & 1,881 \\
Zivot and Andrews & 8 & 1,694 \\
Elliott, Rothenberg and Stock (1996) & 9 & 1,556 \\
Said and Dickey (1984) & 10 & 1,342 \\
\hline
\end{tabular}

Notes: Articles relate to univariate unit root tests. Prominent articles, on a citation basis, involving largely multivariate methods are: Engle and Granger (1987): 12,366; Johansen (1988): 8,236; Johansen and Juselius (1990): 4,886; Johansen (1991): 4,150; and in econometric methods more generally, White (1980), 12,359. (The last article is the most highly cited on the basis of several citation methods.) On the index of economics articles since 1970, compiled by Han Kim et al. (2006), Dickey and Fuller (1979) ranks 7, whilst Engle and Granger (1987) and Johansen (1988) rank 4 and 8, respectively.

Source: Google Scholar, accessed 22 February 2010.

methods of maximum likelihood and generalised least squares (GLS), for example as provided in Greene (2006). An introduction to time series analysis and mathematical statistics would also be useful; for example, for the former at the level of Chatfield (2004) and the latter along the lines covered by Mittelhammer (1996). A book designed especially as a primer for this one is Patterson (2010). Some familiarity with the application of unit root tests would also be helpful to set the context.

I have taken the brief of this book to include issues that are related to but theoretically separate from the central concern of testing for a unit root. For example, one of these is the problem of the bias in estimating the coefficients in an autoregressive model; whilst this is strictly a finite sample effect, it is of practical interest and serves as a 'lead in' to the problems associated with unit testing. This book is, therefore, not about listing tests for a unit root. Not only would there not be enough space for such an enterprise, it is not the best way to indicate which test statistics, and methods more generally, have been taken up by practitioners. The main tests are of course presented and their rationale explained, together with examples to illustrate how they are used. However, the problem suggested by the presence of a unit root or near-unit root is more than just the design of a test statistic. There are two other important practical issues that a researcher has to face. The first is to consider what the appropriate alternative hypothesis is. In the Dickey-Fuller paradigm, followed by many in practice, the alternative to a stochastic trend is a deterministic trend, usually 
characterised as a low order polynomial in time. However, the choice of the order of the polynomial, typically representing reversion to a constant or a linear trend, has a critical effect on the power of the test if over-specified; on the other hand, if under-specified, a test will have no power to detect a true alternative. The representation of the 'attractor' as being generated by a low order polynomial trend is likely to be a shorthand, or reduced form, for a far more complex process. In part, the pre-eminent role of a simple deterministic trend in providing the mean or trend reverting alternative to a non-reverting process (nonstationary by way of a unit root or roots), is historical and, of itself, deserves further study and evaluation.

A second key, practical aspect arises from the usual need to choose some form of a truncation parameter. In the context of the familiar augmented Dickey-Fuller tests, this is a lag truncation parameter and in the context of the semi-parametric tests, which require an estimate of the long-run variance, a parameter limiting the bandwidth in the formation of a sum of autocovariances. Whilst familiar criteria, such as the AIC, BIC and general-to-specific (g-t-s), rules are in frequent use, the combination of each one of these with a test statistic defines test procedures with potentially differing characteristics; their use in combination then leads to the accumulation of type I error.

Some of the developments covered in this book are as follows.

- The distinction between difference stationary and trend stationary processes and the implications of this distinction for the permanence or otherwise of shocks.

- An outline of the autoregressive moving average (ARMA) modelling framework and its role in testing for a unit root.

- The finite sample bias in estimating models and its implications for inference even when seemingly well into the region of stationarity.

- Forming confidence intervals that are robust to the problem of quantiles that are not constant.

- The DF unit root tests and developments of them to account for weak serially correlated processes.

- Bootstrapping confidence intervals and unit root tests.

- Tests that:

- are based on a direct maximum likelihood approach;

- are based on a GLS, or quasi-GLS, approach, including the influential tests by Elliott, Rothenberg and Stock (1996);

- combine the backward and forward recursions of a random walk;

- are based on recursive estimation of the mean or trend;

- are robust to the initial condition;

- allow for more than one unit root; 
- are based on stationarity as the null hypothesis;

- allow for unit roots in seasonal data.

The results of a number of Monte Carlo studies are reported in various chapters. Indeed, simulation is a key tool that is used throughout to provide some guidance on finite sample issues. Consider, for example, the problems caused by the presence of weakly dependent errors when testing for a unit root. Then under fairly weak assumptions, the asymptotic properties of several frequently used test statistics are unaffected by such errors, but typically, the finite sample properties do not reflect the asymptotic properties, an example being the difficulty caused by the near cancellation of a root, especially a near-unit root, in the AR and MA components of an ARMA model. To understand the finite sample nature of such problems, many more simulations were run than are reported in the various chapters; the results are then typically illustrated for one or two sample sizes where they are representative of a wider range of sample sizes.

There are a number of developments and problems not covered in this volume, but which are included in Volume 2 . These include the following.

Nonparameteric tests: the tests that have been considered in this volume, such as the family of Dickey-Fuller tests, are parametric tests in the sense that they are concerned with direct estimation in the context of the parametric structure of an AR or ARMA model. Nonparametric tests use less structure in that no such explicit parametric framework is required and inference is based on other information in the data, such as ranks, signs and runs. Semi-parametric tests use some structure, but it falls short of a complete parametric setting; an example here is the rank score based test, which is based on ranks.

Fractional integration: this considers the case of fractional values of the integration parameter. That is, suppose that a stochastic process generates a time series that is integrated of order $d$, where $d$ is a fractional number. What meaning can we attribute to such an operation and how can the parameter d be estimated? There are two general approaches to the analysis and estimation of fractional I(d) process, as they may be either analysed in the time domain or the frequency domain.

Bounded random walks: the application of random walk models to some economic time series can be inappropriate, as where there are natural bounds or limits to the values that the series can take, such as in the case of unemployment rates and nominal interest rates. One way of modelling this is to allow unit root behavior; for example, persistence and the absence of mean reversion over a range of possible values but reversion at other values. These models have 
in common that they involve some form of nonlinearity. Perhaps the simplest from of nonlinearity actually arises from piecewise linearity; that is, an overall model comprises two or more linear models for subperiods where the component models differ not in their form, for example all are $\operatorname{AR}(p)$, but in their parameters. A popular class of such models is the smooth transition autoregressive - or STAR - class, of which the exponential and logistic members are the most frequent in application, giving rise to the acronyms STAR and LSTAR.

Structural breaks: Perron's (1989) seminal article began another thread of the unit root literature. What if, instead of a unit root process generating the data, there was a trend subject to a break due to 'exceptional' events? How would standard unit root tests perform? For example, what would be their power characteristics, if the break was ignored in the alternative hypothesis? The idea of regime change that could affect led to a fundamental re-evaluation of the simplicity of the simple 'opposing' mechanisms of a unit root process, on the one hand, and a trend stationary process, on the other. In practice, although there are likely to be some contemporaneous and, later, historical indications of regime changes, there is almost inevitably likely to be uncertainty not only about the dating of such changes but also the nature of the changes. This poses another set of problems for econometric applications. If a break is presumed, when did it occur? Which model captures the nature of the break? If multiple breaks occurred, when did they occur?

My sincere thanks go to Lorna Eames, my secretary at the University of Reading, for her unfailing assistance in the many tasks needed to bring the manuscript into shape.

The graphs in this book were prepared with MATLAB www.mathworks.co.uk, which was also used, together with TSP (www.tspintl.com) and RATS (www.estima.com), for the numerical examples. Martinez and Martinez (2002) provide an invaluable guide to statistics with many MATLAB examples; guides to MATLAB include Hanselman and Littlefield (2004), Moler (2004) and Hahn and Valentine (2007).

If you have comments on any aspects of the book, please contact me at my email address given below.

Author's email address: k.d.patterson@reading.ac.uk Palgrave Macmillan Online: http://www.palgrave.com/economics/ Palgrave Macmillan email address: orders@palgrave.com 